Article

\title{
Shrinkage and Durability Evaluation of Environmental Load-Reducing FRPCM by Using Silicone Oil
}

\author{
Hyeonggil Choi ${ }^{1}$, Heesup Choi ${ }^{2} * * \mathbb{D}$, Bokyeong Lee ${ }^{3}$ and Dong-Eun Lee ${ }^{4}$ \\ 1 School of Architecture, Kyungpook National University, 80 Daehakro, Bukgu, Daegu 41566, Korea; \\ hgchoi@knu.ac.kr \\ 2 Department of Civil and Environmental Engineering, Kitami Institute of Technology, 165 Koencho, Kitami, \\ Hokkaido 090-8507, Japan \\ 3 Intelligent Construction Automation Center, Kyungpook National University, 80 Daehakro, Bukgu, \\ Daegu 41566, Korea; bklee11@knu.ac.kr \\ 4 School of Architecture and Civil Engineering, Kyungpook National University, 80 Daehakro, Bukgu, \\ Daegu 41566, Korea; dolee@knu.ac.kr \\ * Correspondence: hs-choi@mail.kitami-it.ac.jp
}

Received: 27 March 2019; Accepted: 11 April 2019; Published: 15 April 2019

check for updates

\begin{abstract}
In this study, the shrinkage and durability of environmental load-reducing fiber-reinforced polymer cement mortar (FRPCM) were examined by using silicone oil. The results indicated that the shrinkage can be greatly reduced by adding silicone oil. However, when the silicone oil is added in excess, it affects the strength and durability. Therefore, it is possible to obtain the ECO-FRPCM which gives the effect of reducing the shrinkage and maintaining the strength and durability by adding $3 \%$ of silicone oil. From the viewpoint of shrinkage reduction, the use of silicone oil is effective as a substitute for an expansive additive or shrinkage reducing agent used in ECO-FRPCM. Also, by appropriately using silicone oil in combination with an expansive additive or a shrinkage reducing agent, shrinkage can be effectively reduced as compared with the conventional ECO-FRPCM. However, when the silicone oil and the shrinkage reducing agent are used in combination, the shrinkage cannot be efficiently reduced. It is considered that the combination of silicone oil and shrinkage reducing agent influences the mutual shrinkage reduction mechanism, but this needs to be further examined in the future.
\end{abstract}

Keywords: FRPCM; silicone oil; expansive additive; shrinkage reducing agent; shrinkage; durability

\section{Introduction}

Since concrete cracks due to shrinkage significantly influence the safety and durability of concrete structures, it is important to identify them [1-3]. Particularly as requirements for long life and high durability of concrete structures have increased in recent years, it is very important to repair these cracks or deteriorated parts efficiently [1-3]. As one of the typical repair materials, fiber-reinforced polymer cement mortar (FRPCM) has been researched and developed, and is now commercialized and used as a well-known repair material for cracks or deterioration [4,5]. FRPCM is a material that can block the deterioration factors by efficiently repairing cracks through the crack control and toughness improvement effect through the fibers and excellent adhesion due to the polymer [4-6].

In the meantime, environmental-load-reducing FRPCM (ECO-FRPCM), in which ground-granulated blast furnace slag (an industrial by-product) is added as a binder to reduce the environmental loads, has been developed in recent years $[7,8]$. However, when ground-granulated 
blast furnace slag is used as a binder, it causes a problem in strength development and an increase in shrinkage at the early curing stage and acceleration of concrete carbonation in the long term [9].

Moreover, it has been reported that the silicone oil is used for a cementitious material, thereby improving the carbonation and drying shrinkage resistance due to the water repellency of the silicone oil [10-13].

Thus, this study investigated the shrinkage characteristics, strength characteristics, and durability with addition of a silicone oil, which was found to be excellent in shrinkage reduction effect or resistance against carbonation, to the FRPCM to overcome the drawback of ECO-FRPCM (with added ground-granulated blast furnace slag). The study also investigated the shrinkage characteristics of ECO-FRPCM where a silicone oil was added (as a substitute of an expansive additive or shrinkage-reducing agent) that was known to have the shrinkage reduction effect.

\section{Experimental Program}

\subsection{Outline of Experiment}

Tables 1-3 shows the materials used, binding materials properties and experimental compositions. The ECO-FRPCM used in this experiment employed ground-granulated blast furnace slag as fine aggregates and binder, and expansive additive and shrinkage-reducing agent were added as shrinkage reducing materials. Experiments were conducted by referring to the mix design of ECO-FRPCM, in which the content ratio of the ground-granulated blast furnace slag was set to $35 \%$, silica fume was set to $5 \%$, polymer set to $2 \%(\mathrm{~B} \times \mathrm{wt}$. $\%$ ), water-cement ratio was $36 \%$, slag-to-binder ratio $(\mathrm{S} / \mathrm{B})$ was 1 , and 0.5 vol. $\%$ of polypropylene fiber $(6 \mathrm{~mm})$ was admixed $[7,8]$. Further, antifoaming agent, air entraining agent, and water reducing agent were added to control the flash property. In Series I, the effects of the addition of the silicone oil on the performance of ECO-FRPCM were investigated. The addition rate of the silicone oil was set to five levels $(0 \%, 1 \%, 3 \%, 5 \%$, and $10 \%)$, and slump flows, strength characteristics, cure shrinkage, carbonation, and freeze-thaw resistance were evaluated for each. In Series II, the effects of the combining use of silicone oil-added ECO-FRPCM with the expansive additive and shrinkage-reducing agent on the strength and shrinkage characteristics were evaluated to investigate the effect of substitution of the expansive additive and shrinkage reducing agent by the silicone oil. The specimens were made by fixing the silicone oil addition to $3 \%$ while controlling the addition of the expansive additive and shrinkage reducing agent to have four types of specimens in the experiment. Mixing of FRPCM was performed that all materials put in the pan type mixer excluding antifoaming agent, and then the pre-mixing was performed for $30 \mathrm{~s}$ and main mixing was conducted for $3 \mathrm{~min}$. Afterwards, an antifoaming agent was placed in the mixer and the mixing was performed for 1 additional minute. After confirming that the fibers were uniformly mixed, a specimen was prepared.

Table 1. The materials Used.

\begin{tabular}{|c|c|}
\hline & Type \\
\hline Binder & $\begin{array}{l}\text { Ordinary Portland cement (OPC), Density: } 3.17 \mathrm{~g} / \mathrm{cm}^{3} \\
\text { Blast furnace slag (BFS), Blaine: } 4000 \mathrm{~cm}^{2} / \mathrm{g} \text {, Density: } 2.89 \mathrm{~g} / \mathrm{cm}^{3} \\
\text { Silica fume (SF), Density: } 2.25 \mathrm{~g} / \mathrm{cm}^{3} \\
\text { Expansive additive (E), Ettringite type, Density: } 2.93 \mathrm{~g} / \mathrm{cm}^{3}\end{array}$ \\
\hline sand & Blast furnace slag sand, Density: $2.66 \mathrm{~g} / \mathrm{cm}^{3}$, Grain size: $0.6 \sim 1.2 \mathrm{~mm}$ \\
\hline Admixture & $\begin{array}{c}\text { Polymer (P), Acetic acid acrylic type, Density: } 1.05 \mathrm{~g} / \mathrm{cm}^{3} \\
\text { Shrinkage reducing agent (SRA), Powder type nonionic mixture } \\
\text { Antifoaming agent (AA), Poly ether type } \\
\text { Air entraining agent (AE), Aliphatic alcohol type, Density: } 1.04 \sim 1.08 \mathrm{~g} / \mathrm{cm}^{3} \text {, Total alkali } \\
\text { amount (\%): } 3.7 \\
\text { Water reducing agent (WRA), Poly carboxylic type } \\
\text { Silicone oil (SO), Density: } 0.96 \mathrm{~g} / \mathrm{cm}^{3}, \text { Viscosity }\left(25^{\circ} \mathrm{C}\right): 20 \mathrm{cst} \text {, Refractive index: } 1.42\end{array}$ \\
\hline Fiber & Polypropylene (PP): Length: $6 \mathrm{~mm}$, Diameter: $42.6 \mu \mathrm{m}$, Density: $0.91 \mathrm{~g} / \mathrm{cm}^{3}$ \\
\hline
\end{tabular}


Table 2. Binding materials properties.

\begin{tabular}{|c|c|c|c|c|c|c|c|c|c|c|}
\hline \multirow{2}{*}{ Binder } & \multirow{2}{*}{$\begin{array}{c}\text { Specific Surface } \\
\text { Area }\left(\mathrm{g} / \mathrm{cm}^{3}\right)\end{array}$} & \multirow{2}{*}{$\begin{array}{l}\text { Density } \\
\left(\mathrm{g} / \mathrm{cm}^{3}\right)\end{array}$} & \multicolumn{8}{|c|}{ Chemical Composition (\%) } \\
\hline & & & $\mathrm{SiO}_{2}$ & $\mathrm{Al}_{2} \mathrm{O}_{3}$ & $\mathrm{Fe}_{2} \mathrm{O}_{3}$ & $\mathrm{CaO}$ & $\mathrm{MgO}$ & $\mathrm{SO}_{3}$ & $\mathrm{f}-\mathrm{CaO}$ & Ig.loss \\
\hline OPC & 3500 & 3.17 & 21.4 & 5.5 & 2.8 & 64.3 & 2.1 & 1.9 & 0.25 & 0.56 \\
\hline BFS & 4000 & 2.89 & 34.0 & 14.4 & 0.83 & 43.3 & 6.5 & - & - & 0.1 \\
\hline $\mathrm{E}$ & 3260 & 2.93 & 21.0 & 5.2 & 0.8 & 70.6 & - & 18.5 & 49.8 & 1.58 \\
\hline SF & - & 2.25 & 96.50 & 0.46 & 0.13 & 0.37 & 0.37 & - & - & 1.83 \\
\hline
\end{tabular}

Table 3. Experimental compositions.

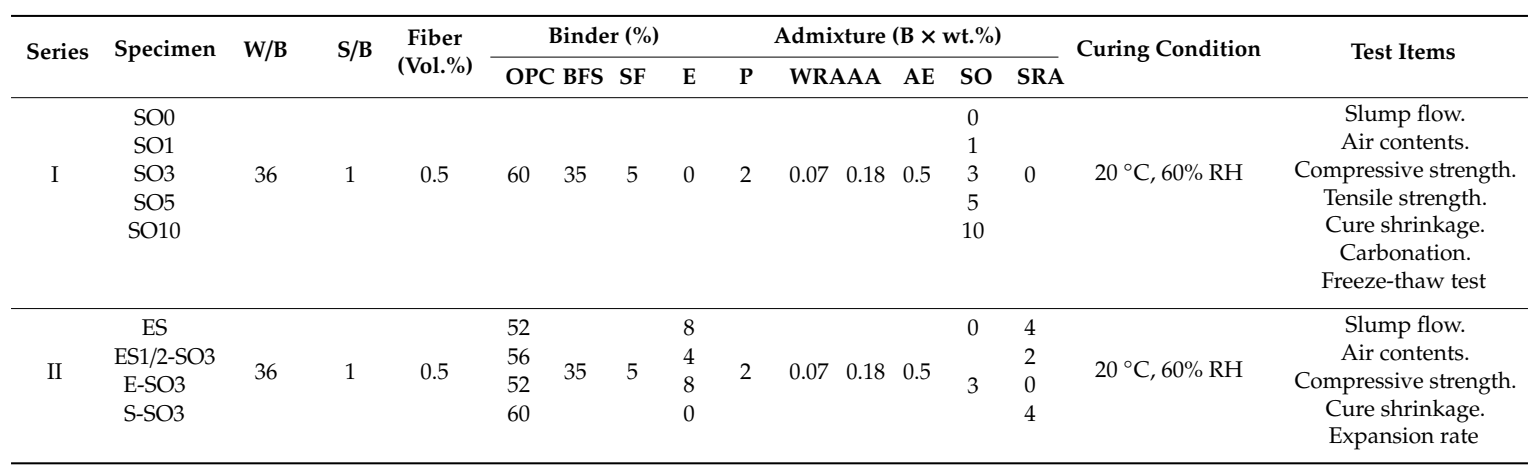

\subsection{Experiment Method}

Slump flow immediately after mixing and air content were measured for the properties of the fresh concrete [14,15]. The specimens for the strength test were $\varnothing 50 \mathrm{~mm} \times 100 \mathrm{~mm}$ cylindrical specimens, which were demolded at an age of 1 day and cured in the constant temperature and humidity chamber at $20{ }^{\circ} \mathrm{C}$ and $60 \%$ relative humidity. Then, the compressive strength was measured at $3,7,28$, and 91 days according to JIS A1108 [16]. The tensile strength was measured as follows: a dumbbell-shaped thin specimen was fabricated as shown in Figure 1 and cured under the same environment as that of the compressive strength specimens to have a constant strain by controlling loading rate at $0.5 \mathrm{~mm}$ per sec. The direct tensile strength was then measured at 28 days using the universal tester [17].
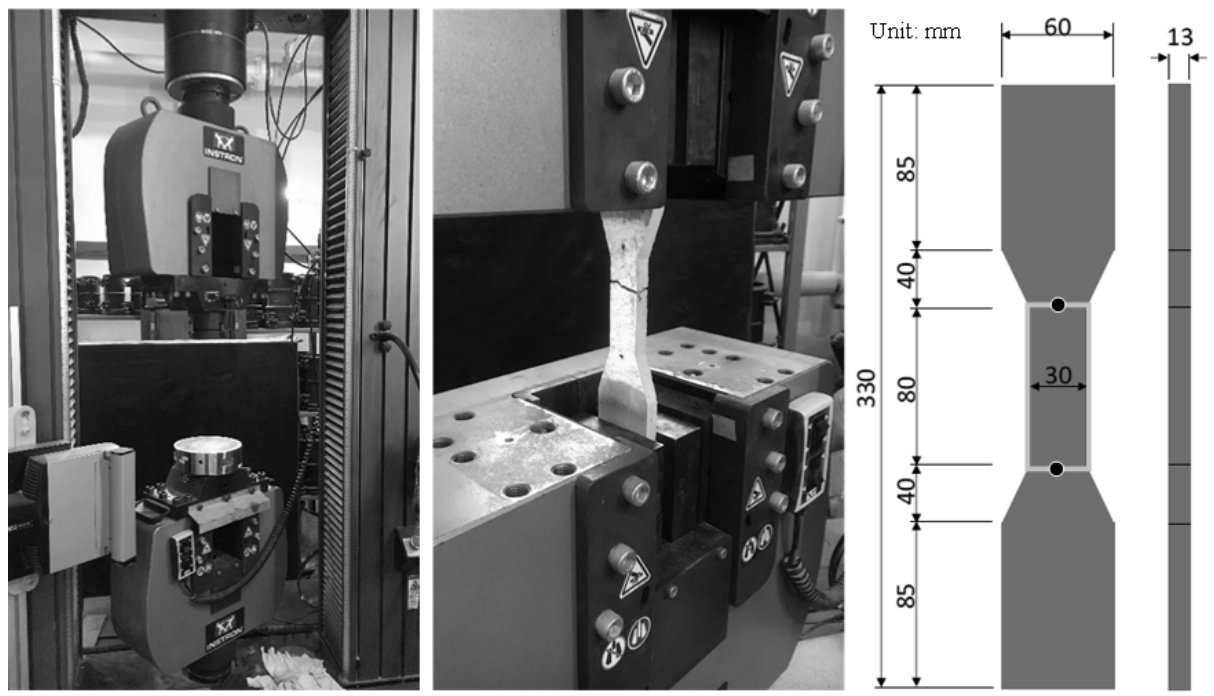

Figure 1. Tensile strength testing machine and size of the specimen.

The length change experiment was conducted by referring to the NEXCO test method 432 [18], which is a curing shrinkage test method of mortar for spray-coating to repair a cross-section, to fabricate 
a prism specimen $(40 \mathrm{~mm} \times 40 \mathrm{~mm} \times 160 \mathrm{~mm})$. This was then demolded at two days and cured in a constant temperature and humidity chamber at $20^{\circ} \mathrm{C}$ and $60 \%$ relative humidity. In the experiment to measure length-change of curing shrinkage and mass-change rate was conducted in accordance with JIS A 1129-3 [19] by shifting the dial gage method up to the pre-determined age.

In the meantime, the curing shrinkage experiment of NEXCO test method 432 [18] did not consider the shrinkage and expansion properties until the demolding time (at two days). Thus, it was particularly important to identify the expansion phenomenon at the early stage if the expansive additive was used. In this regard, the expansion rate up to two days after fabrication was measured in the sealed curing condition at $20^{\circ} \mathrm{C}$ by attaching a $10-\mathrm{mm}$-long strain gage to the $\varnothing 100 \mathrm{~mm} \times 200 \mathrm{~mm}$ cylindrical form (summit mold), as shown in Figure 2, in accordance with JIS A 009-2012 [20] to verify the expansion rate at the early stage.

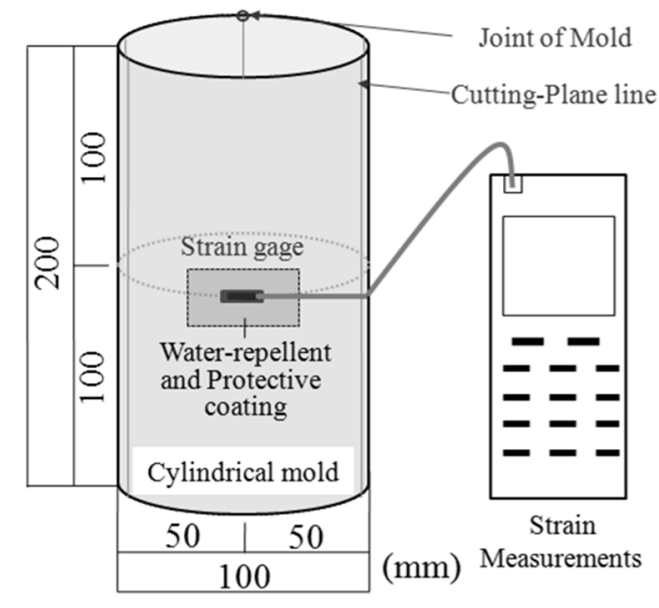

(a)

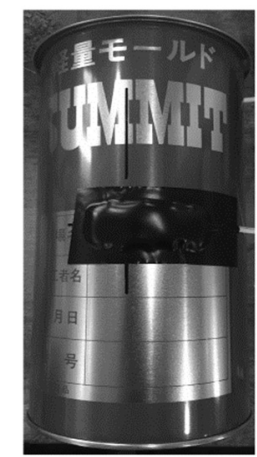

Summit mold

(Cylindrical mold)

$ø 100 \times 200 \mathrm{~mm}$, Gage Length : $10 \mathrm{~mm}$

(b)

Figure 2. Overview of expansion rate test [20]. (a) Outline of the measurement of expansion rate; (b) Summit mold.

The accelerated carbonation test was conducted to measure the carbonation resistance of concrete using a prism specimen $(40 \mathrm{~mm} \times 40 \mathrm{~mm} \times 160 \mathrm{~mm})$ in accordance with JIS A 1153 [21]. The accelerated conditions were $20 \pm 2{ }^{\circ} \mathrm{C}, 60 \pm 5 \%$ of humidity, and $5 \pm 0.2 \%$ of $\mathrm{CO}_{2}$ concentration. The freezing and thawing test was conducted in accordance with JIS A 1148 Procedure A (Rapid Freezing and Thawing in Water) [22] to set the freezing temperature to $-18^{\circ} \mathrm{C}$ and the thawing temperature to $5^{\circ} \mathrm{C}$. One cycle was set to $3 \mathrm{~h}$, and measurements were conducted for up to 300 cycles and the relative dynamic elastic modulus was measured every 30 cycles.

\section{Experiment Result and Discussion}

\subsection{Study on the Effect of Silicone Oil on the Performance of Environmental-Load-Eeducing FRPCM (Series I)}

\subsubsection{Fresh Property and Strength Characteristics}

Figure 3 shows the slump flow and air content results as fresh concrete properties. Since SO0 employed an antifoaming agent to control the air content, its air content was relatively small. However, as the silicone oil addition increased, the slump flow and air content tended to decrease slightly overall. This was because the silicone oil was added as an inner percentage to the mixed water equal to the chemical admixture, so the mixed water amount was reduced as the addition of silicone oil increased. 


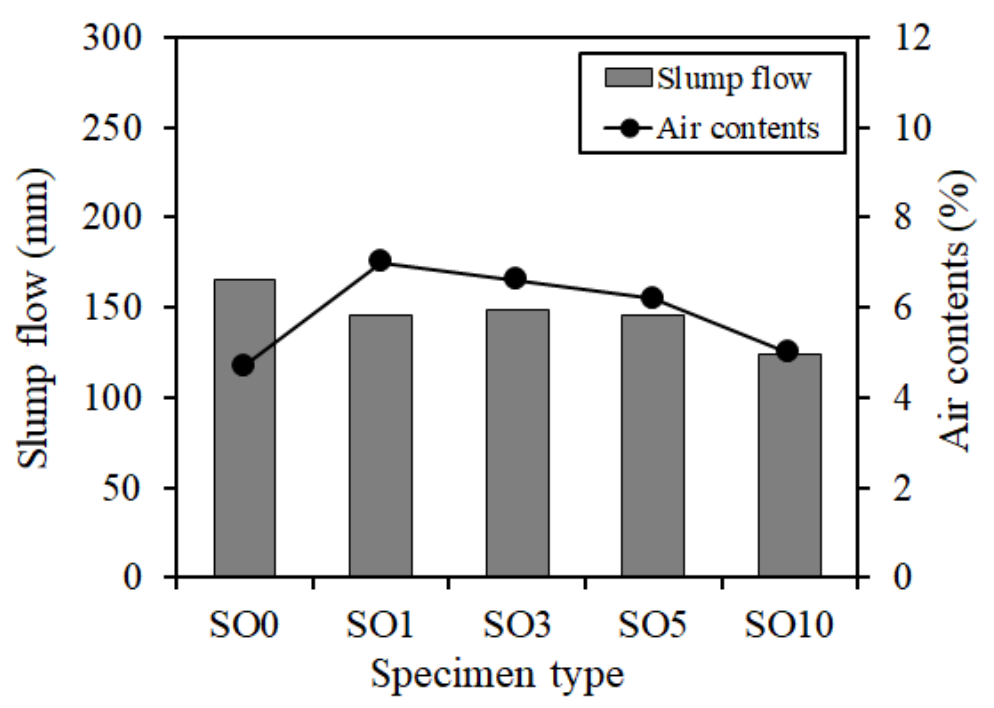

Figure 3. Fresh properties.

Figure 4 shows the test results of compressive strength. As the silicone oil was added, the compressive strength was degraded. Thus, the compressive strength of SO10 was reduced by $40 \%$ of that of SO0 approximately at the age of 91 days, indicating that care should be taken to the reduction in strength when too much silicone oil was added.

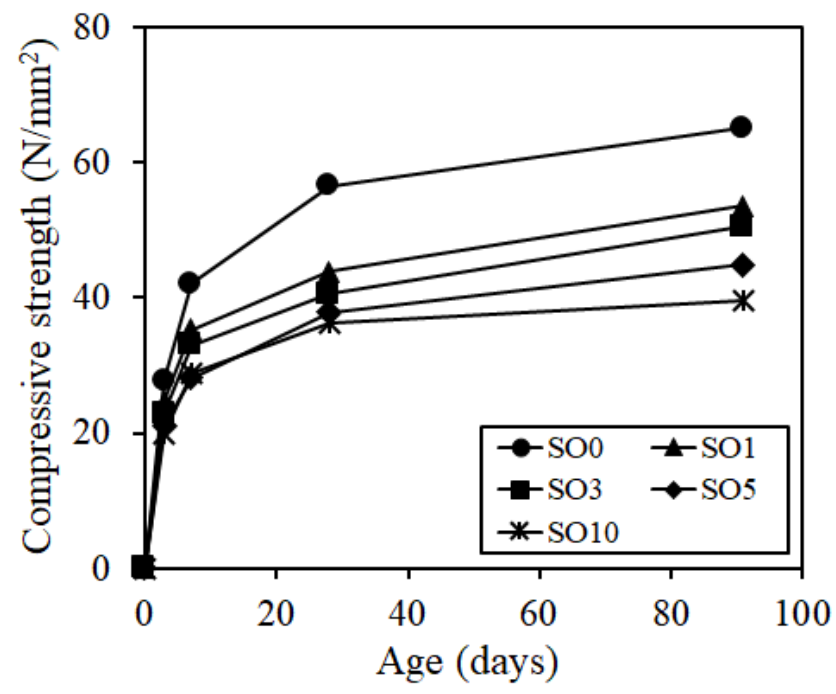

Figure 4. Compressive strength.

For the tensile strength, only the results from fractured specimens within the target fracture point (center $80 \mathrm{~mm}$ ) were summarized, which are shown in Figure 5. The tensile strength tended to decrease the same amount as the compressive strength as the silicone oil was added. 


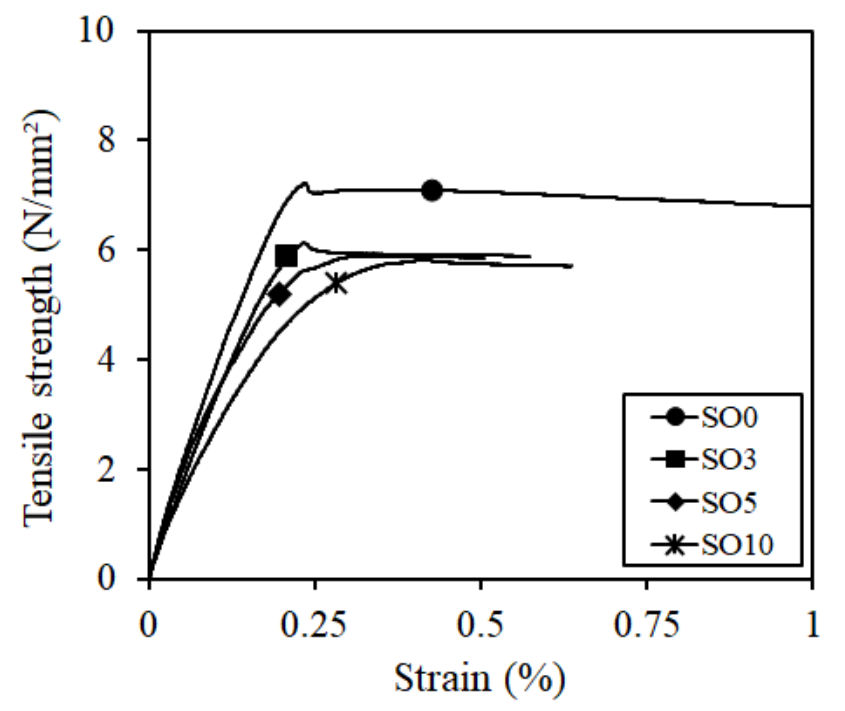

Figure 5. Tensile strength.

The scanning electron microscope observation was conducted in the fracture surface of $\mathrm{SO} 0$ and SO10 to investigate the cause of the strength reduction. The results are presented in Table 4. SO10 verified that the fiber was pulled out while maintaining its shape as the adhesion between the fiber and matrix was degraded due to the silicone oil. Compared to the above phenomenon in SO10, the adhesion between the fiber and matrix in SO0, which did not add silicone oil, was strong, so that the trace of resistance to the matrix around the fiber was verified. Thus, the reduction in adhesion between the fiber and matrix due to the addition of silicone oil was considered to have an impact on the strength characteristics, although additional investigation on this is needed.

Table 4. Scanning electron microscope observation.

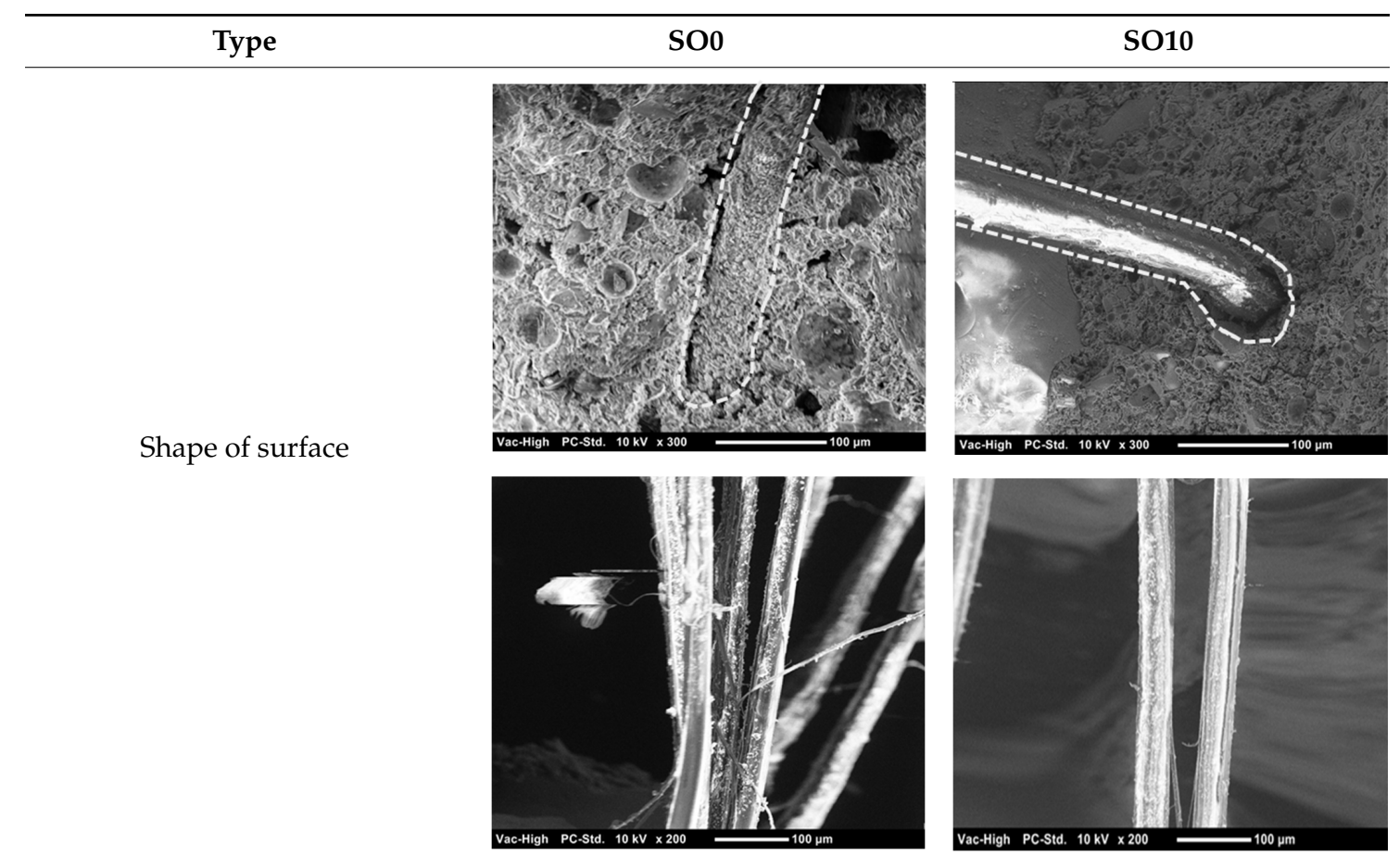




\subsubsection{Shrinkage and Durability Properties}

The results of length and mass change rates up until the age of 91 days are shown in Figures 6 and 7. As verified in Figure 6, as the silicon oil content increased, the shrinkage was significantly degraded, with the shrinkage of SO10 being reduced more by $705 \times 10^{-6}$ (about $58 \%$ ) compared to that of SO0 at the age of 91 days. In the meantime, the mass change rate verified that the length change rate of the silicone oil-added specimen was smaller than that of the specimen without the addition of silicone oil at an early age, but those of $\mathrm{SO} 5$ and $\mathrm{SO} 10$ were similar with that of $\mathrm{SO} 0$ as the age passed, which did not verify a significant correlation. Generally, the shrinkage reducing mechanism occurs due to the reduction in surface tension of pore solution or changes in pore structure. Thus, as a pore diameter is smaller, the capillary tension becomes larger, thereby increasing the shrinkage [23]. When pores whose diameter is different are adjacent, moisture inside the pores is moved to a smaller-diameter pore due to capillarity. However, if silicone oil, which is water repellent, is added, the pore wall will have the water repellent property, resulting in difficulties in moisture travel to a smaller diameter pore, but easy moisture travel to a larger diameter pore $[13,24]$. Accordingly, as the capillary tension inside the pore was smaller, shrinkage was likely to be reduced significantly. Thus, although there was no significant correlation between general mass change rate and shrinkage, the change in moisture travel inside the matrix influenced the shrinkage phenomenon according to the addition of silicone oil.

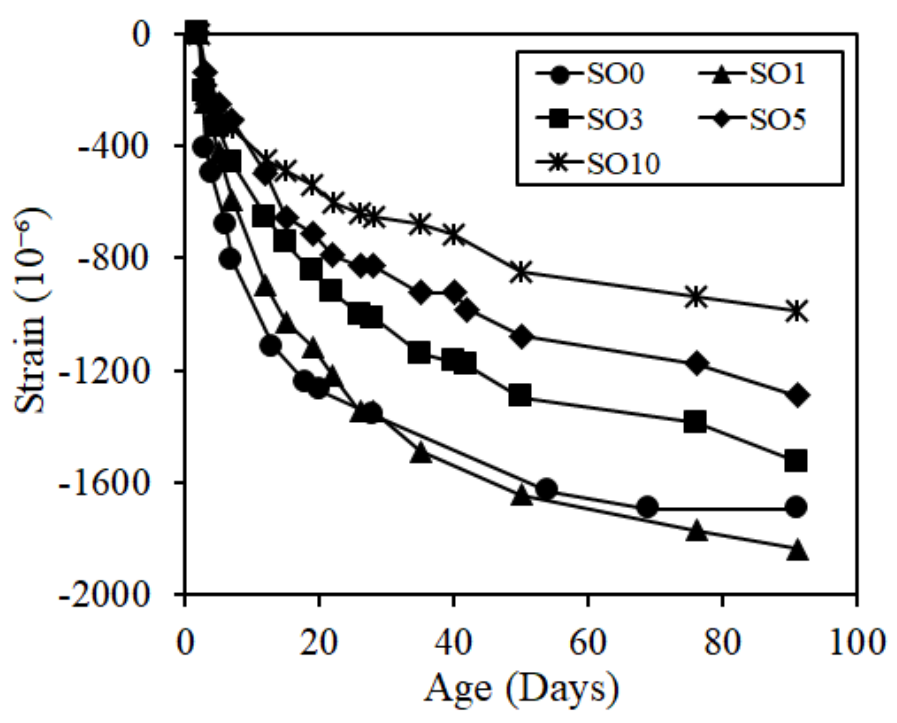

Figure 6. Cure shrinkage.

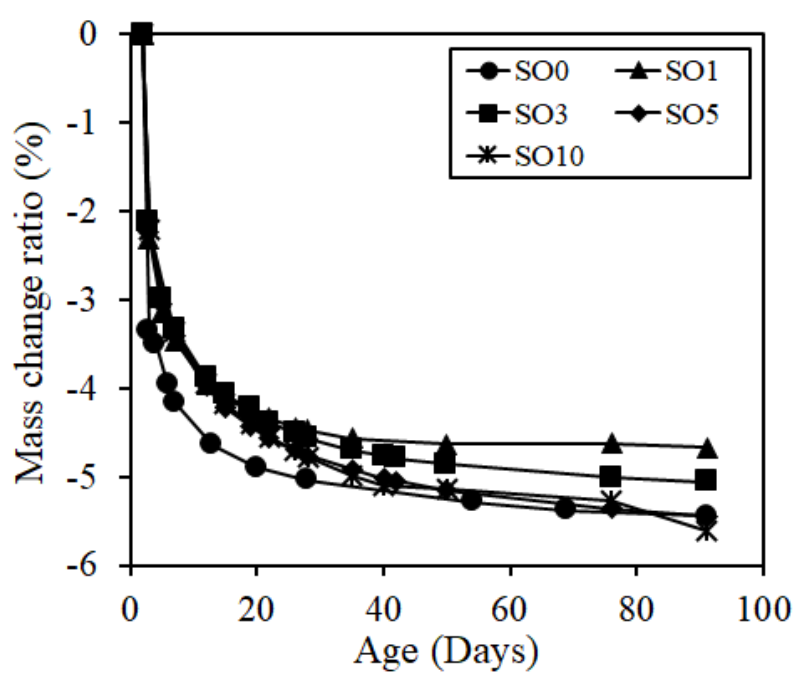

Figure 7. Mass change ratio. 
The accelerated carbonation test results are presented in Table 5. The progress of carbonation is a reaction that is significantly affected by the moisture condition inside the material [25]. A previous study reported that the water repellent effect caused by the silicone oil reduced the adsorption water inside the material, thereby restraining carbonation [24]. However, carbonation was not verified at the age of eight weeks in the accelerated carbonation test. The carbonation effect according to the presence of silicone oil could not be verified as the carbonation of ECO-FRPCM was difficult inherently due to the fiber reinforcement, but the carbonation suppression effect was expected in the long-term age.

Table 5. Carbonation depth.

\begin{tabular}{|c|c|c|c|c|}
\hline Type & $\mathrm{SO} 0$ & SO1 & S03 & S05 \\
\hline 4 weeks & & & & \\
\hline 8 weeks & & & & \\
\hline
\end{tabular}

The freeze-thaw test results are shown in Figure 8. SO0, to which silicone oil was not added, maintained $100 \%$ of the relative dynamic elastic modulus even at the time when 300 cycles were passed whereas the relative dynamic elastic modulus of silicone oil-added $\mathrm{SO} 3$ or $\mathrm{SO} 5$ specimen tended to decrease somewhat. The previous studies [13,24] explained that the water pressure reducing mechanism due to the entrained air was not working, which was inherently expected, as the movement of non-frozen water was reduced due to the silicone oil when the moisture inside the capillary pore was frozen because silicone oil is present as a form of oil droplet inside the pore if the silicone oil is added. The same tendency could also be verified in ECO-FRPCM.

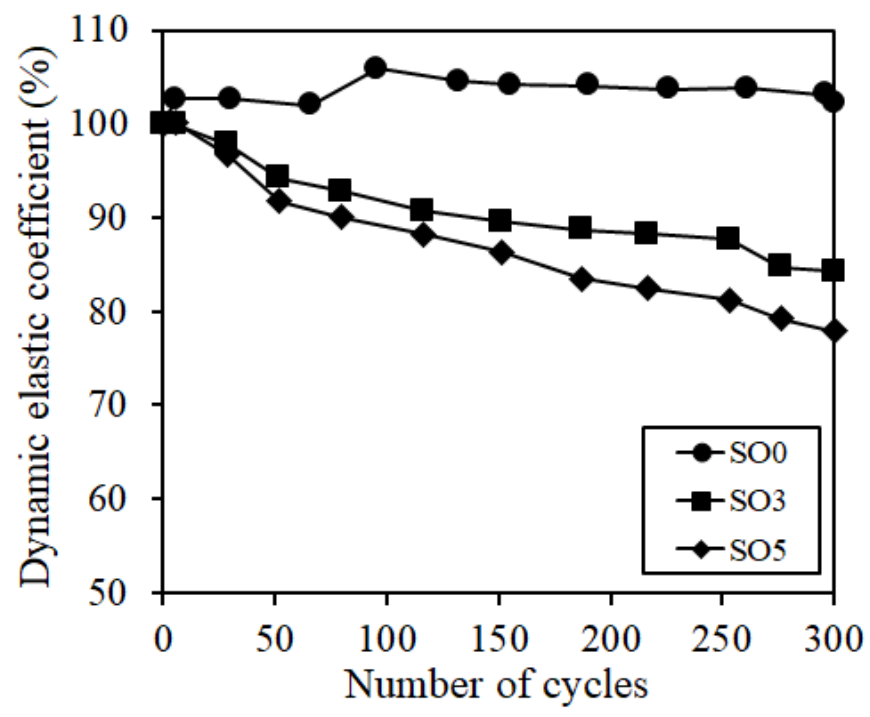

Figure 8. Dynamic elastic coefficient. 
As described above, when silicone oil was added to ECO-FRPCM, shrinkage could be reduced significantly as the addition increased from the viewpoint of shrinkage reduction. However, the strength or durability was degraded if excessive silicone oil was added. Considering this, the proper amount of silicone oil addition was regarded as around 3\%. Based on this result, the silicone oil addition was set to 3\% constantly in Series II and the effect of silicone oil as a replacement of expansive additive or shrinkage reducing agent on the strength and shrinkage characteristics of ECO-FRPCM was evaluated.

\subsection{Investigation of Silicone oil Effect as a Replacement of Expansive Additive and Shrinkage Reducing} Agent (Series II)

\subsubsection{Fresh Property and Strength Characteristics}

Figure 9 shows the results of the fresh concrete properties. The figure verified that as the silicone oil was added, a slump flow had no significant change and the air content tended to decrease slightly, but the result satisfied the range of target air content $(6.0 \pm 1.5 \%)$.

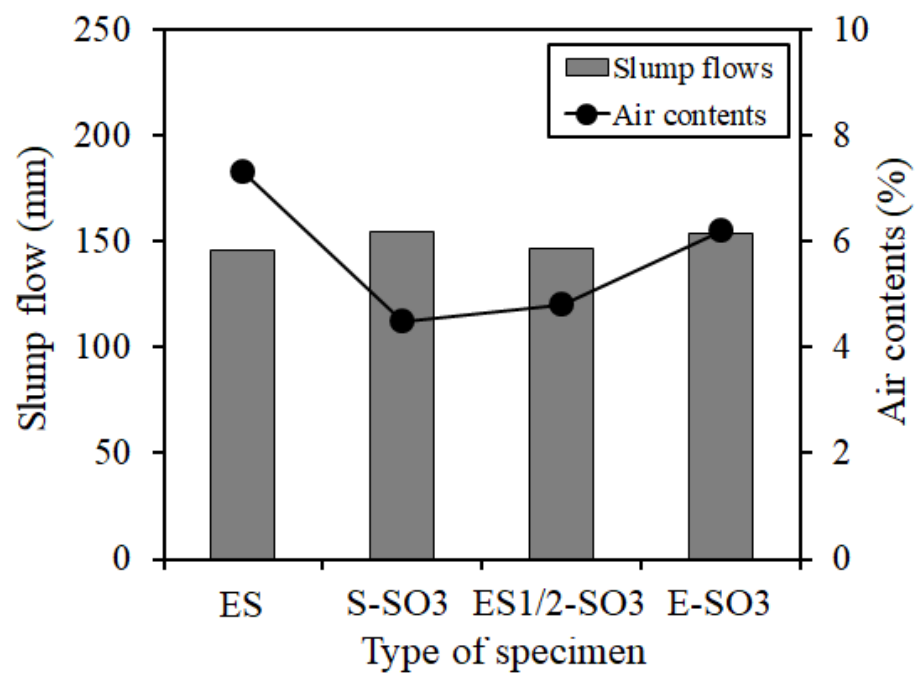

Figure 9. Fresh properties.

Figure 10 shows the results of the compressive strength test. The compressive strength of the specimen with the addition of silicone oil was reduced slightly at the age of 91 days, but the difference was minimal.

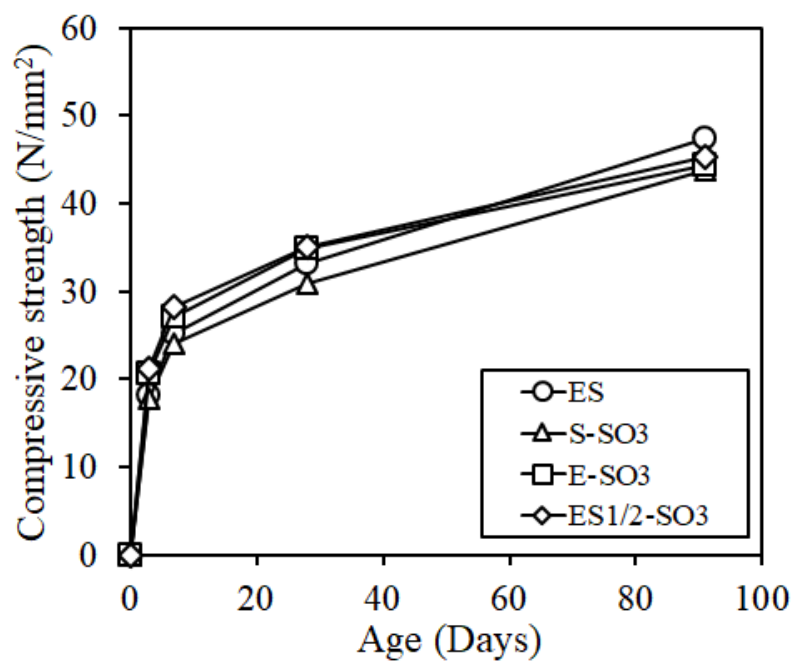

Figure 10. Compressive strength. 
Thus, the silicone oil as a replacement of expansive additive or shrinkage reducing agent used in ECO-FRPCM for the effect of shrinkage reduction should have no significant problem in constructability and strength development if the addition was in a range of $3 \%$.

\subsubsection{Shrinkage Properties}

The expansion rate test was conducted with specimens mixed with expansive additive to verify the expansion effect at an early age when the expansive additive was mixed. The results are shown in Figure 11. As the reference results, Figure 11 also shows the results of SO0 to which the expansive additive was not added. The figure verified the expansion rate at an early age according to the expansive additive content, and specimens where the expansive additive was not mixed did not show the expansion.

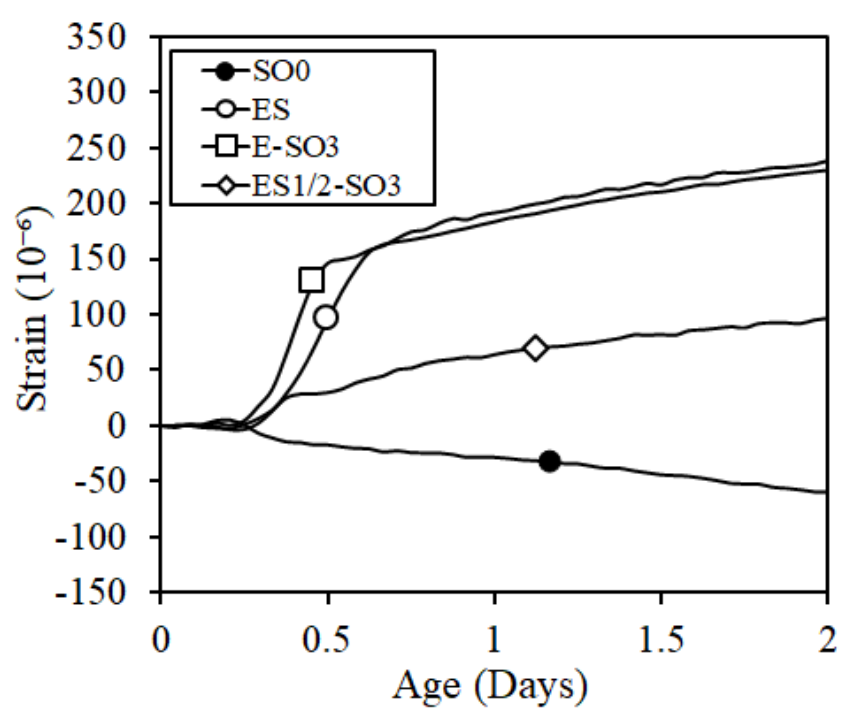

Figure 11. Expansion rate.

Figure 12 shows the results of the length change results in the cure shrinkage test. At the age of 28 days, the specimens of ES1/2-SO3 and E-SO3 showed a smaller value than $500 \times 10^{-6}$, which was the reference value of dimensional stability of repair material, which satisfied the reference value, but ES where silicone oil was not added, and S-SO3 where the shrinkage reducing agent and silicone oil were both added, did not satisfy the reference value. In addition, the shrinkage of ES1/2-SO3 where the expansive additive, shrinkage reducing agent, and silicone oil were added was approximately $750 \times 10^{-6}$ at the age of 91 days, which verified that the effect of shrinkage reduction was the largest under these conditions. The length change results considering the early expansion phenomenon is shown in Figure 13. The figure verified that the ES specimen, which was a mix of ECO-FRPCM, satisfied the reference value at the age of 28 days by considering the early expansion phenomenon, and all the ES1/2-SO3, E-SO3, and ES specimens had a shrinkage around $600 \times 10^{-6}$ at the age of 91 days. However, the shrinkage of S-SO3, to which shrinkage reducing agent and silicone oil were added, increased at a significant rate at all ages compared to other levels. Thus, a difference of more than $400 \times 10^{-6}$ was exhibited compared to other specimens at the age of 91 days. 


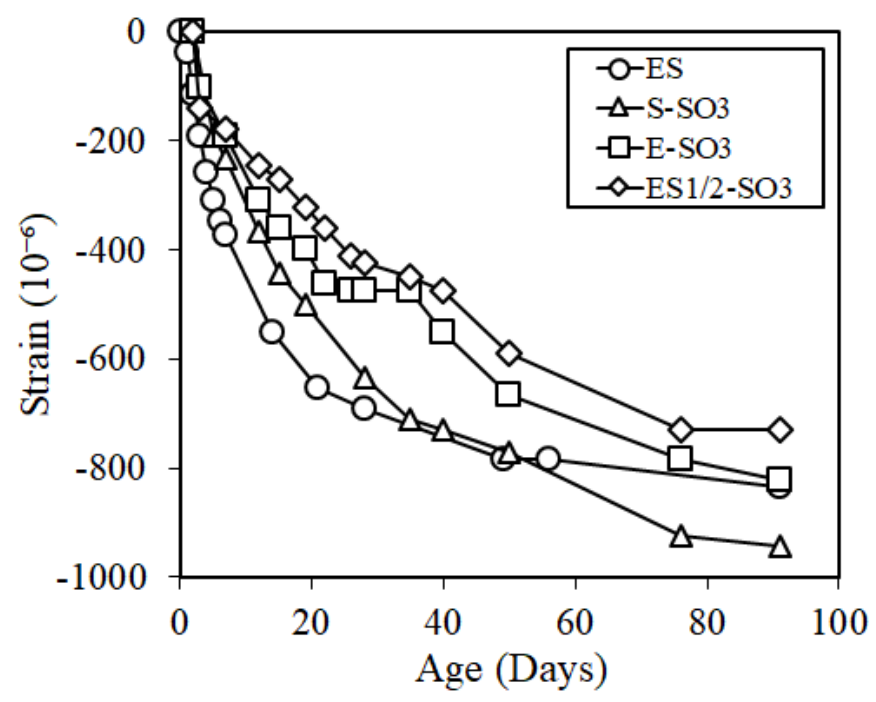

Figure 12. Cure shrinkage.

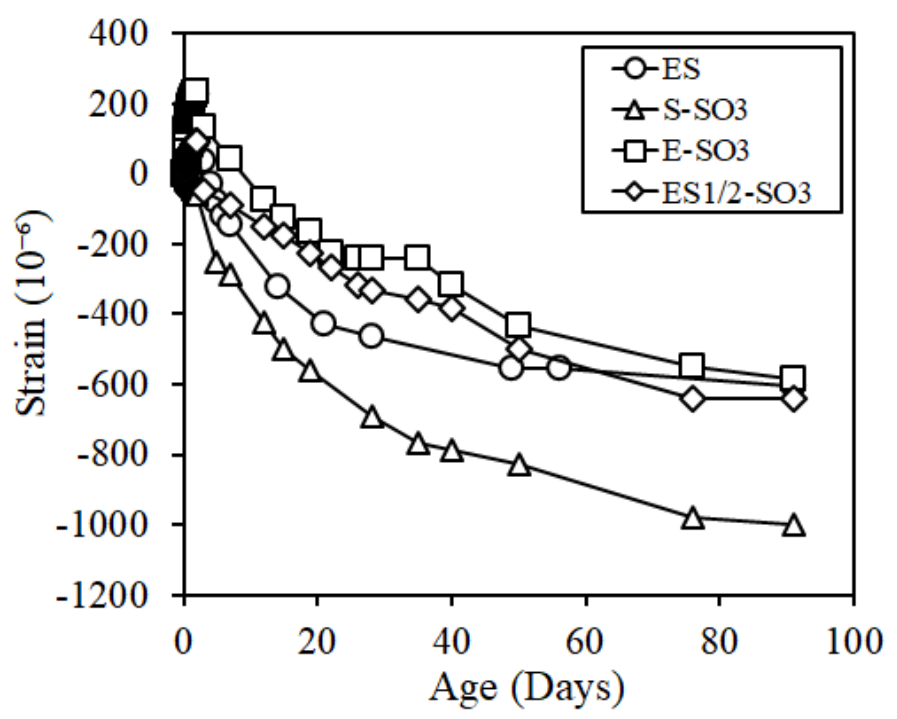

Figure 13. Cure shrinkage considering the early expansion.

In the meantime, the effects of shrinkage reduction by silicone oil were investigated summarizing the author's previous study results [8] and the experimental results. The length change rate and shrinkage reduction results at the age of 28 days are shown in Figure 14. The SO0 and SO3 specimens, to which silicone oil was added singly, and E-SO0 and E-SO3 specimens, to which both of silicone oil and expansive additive were added, had the shrinkage reduction effect of $14.1 \%$ and $44.8 \%$, respectively whereas the shrinkage of S-SO0 and S-SO3 specimens, to which both of silicone oil and shrinkage reducing agent were added, tended to rather increase by $23.8 \%$. This was due to the difference in the shrinkage reducing mechanism between silicone oil and shrinkage reducing agent. That is, the shrinkage occurs due to the change in the surface tension of pore solution generally as shown in Figure 15, and the smaller the pore diameter was, the larger the shrinkage was as the capillary tension increased (a). In the meantime, silicone oil exhibited the shrinkage reducing effect through the water-repellent performance (b), and the shrinkage reducing agent reduced the surface tension of the pore solution inside the capillary pore thereby exhibiting the shrinkage reducing effect (c). Here, when both the silicone oil and shrinkage reducing agent were added, the interfacial activation action via the shrinkage reducing agent alleviated the water-repellent property of silicone oil as well as changing the surface tension inside the pore and water movement inside the pore of the hardened body, thereby 
affecting the mutual shrinkage reducing mechanism between silicone oil and the shrinkage reducing agent, resulting in no efficient shrinkage reduction. However, this needs to be studied in the future.

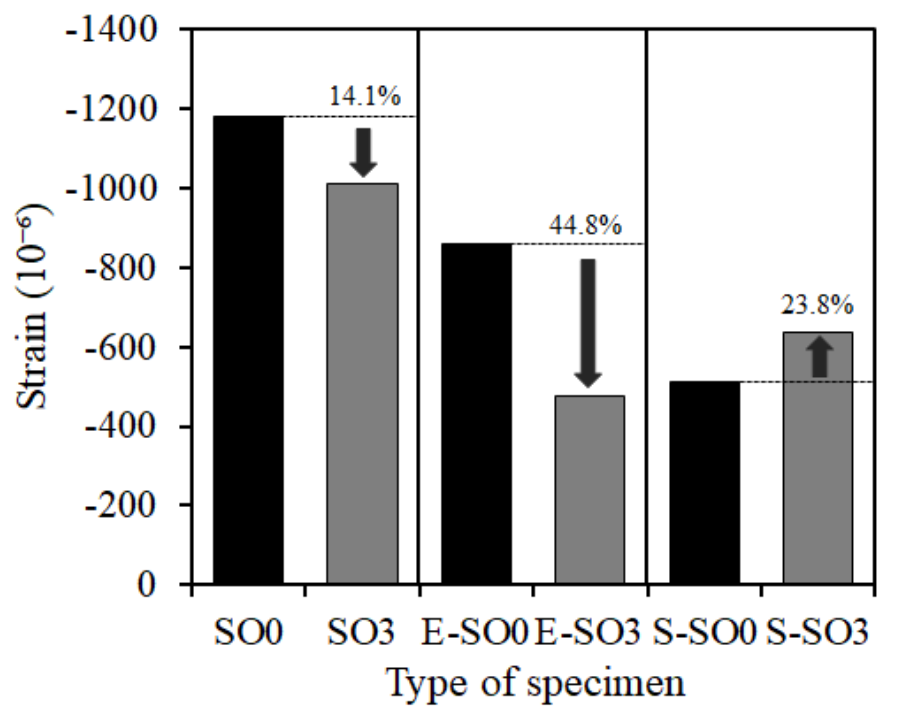

Figure 14. Shrinkage reduction effect of silicon oil in ECO-FRPCM.

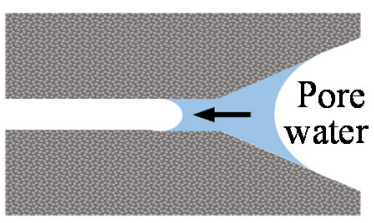

(a) Move to small diameter due to capillary phenomenon

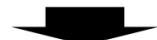

Shrinkage occurs

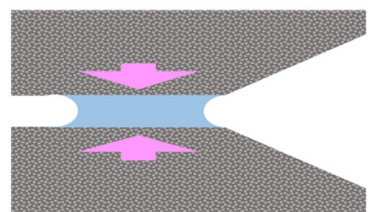

Attract each other by surface tension

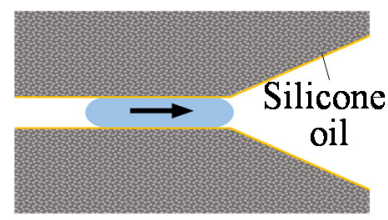

(b) Moving pore water to coarse diameter due to water repellency

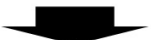

Shrinkage reduction effect by the silicone oil

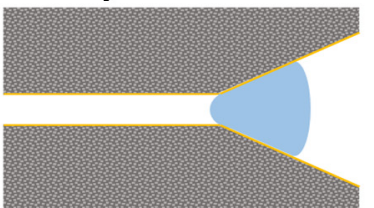

Shrinkage fits in the small diameter part

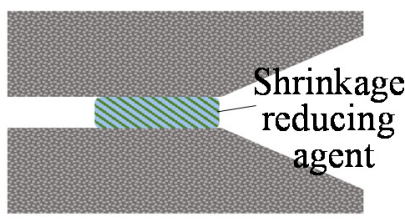

(C) Adjust surface tension

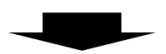

Shrinkage reduction effect by the SRA

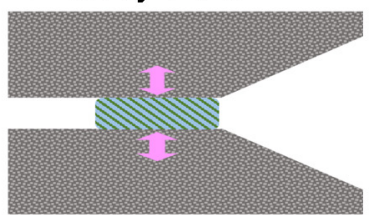

Role as surfactant

Figure 15. Shrinkage reduction effect.

\section{Conclusions}

This study investigated the shrinkage characteristics and durability of silicone oil-added environmental-load-reducing FRPCM, and the following conclusions were obtained.

(1) A shrinkage reduction effect at a significant rate could be obtained as the silicone oil content increased. However, excessive addition may affect the strength and durability. Thus, approximately $3 \%$ of silicone oil content was appropriate to develop strength and maintain durability while obtaining ECO-FRPCM that had the shrinkage reduction effect.

(2) The use of silicone oil as a replacement of expansive additive or shrinkage-reducing agent used in ECO-FRPCM was effective in terms of shrinkage reduction. In particular, equivalent or better shrinkage-reducing effect could be obtained by combining both silicone oil and expansive additive, or by combining silicone oil, expansive additive, and shrinkage-reducing agent. 
(3) When silicone oil and the shrinkage reducing agent were combined, the inherent shrinkage-reduction effects of each were difficult to distinguish. This may affect each of the shrinkage-reducing mechanisms, such as alleviating not only the water-repellent property of silicone oil, but also moisture travel inside the pores of the hardened body and changes in surface tension, resulting in inefficient shrinkage reduction. However, this finding requires additional study in the future.

Author Contributions: H.C. (Hyeonggil Choi) and H.C. (Heesup Choi) conceived and designed the experiments; H.C. (Hyeonggil Choi) performed the experiments; H.C. (Hyeonggil Choi), H.C. (Heesup Choi) and B.L. analyzed the data; D.L. contributed analysis tools. All authors contributed in manuscript preparation and participated in revising the article critically for important intellectual content.

Funding: This work was supported by the National Research Foundation of Korea (NRF) grant funded by the Korea government (MSIT) (No. NRF-2018R1A5A1025137).

Conflicts of Interest: The authors declare no conflict of interest.

\section{References}

1. KCI. Korea Structural Concrete Design Code; Korea Concrete Institute: Seoul, Korea, 2012.

2. AIJ. Recommendations for Practice of Crack Control in Reinforced Concrete Buildings (Design and Construction); Architectural Institute of Japan: Tokyo, Japan, 2006.

3. JCI. Research Committee Report on Shrinkage of Concrete; Japan Concrete Institute: Tokyo, Japan, 2010.

4. Kwon, M.H.; Jung, W.Y.; Seo, H.S. The Flexural Strength of Fiber-Reinforced Polymer Cement Mortars Using UM Resin. Int. Sch. Sci. Res. Innovation. 2014, 8, 127-130.

5. Chen, W.D.; Zhong, S.Y. Influences of Processing and Testing Conditions on Flexural Behavior of Fiber-Reinforced Polymer-Modified Cement Mortar. Adv. Mater. Res. 2013, 687, 502-507. [CrossRef]

6. Deepak, H.; Joy, S.; Vasugi, V. Repair Mortar for Structural Sustainability. Indian J. Sci. Technol. 2016, 9, 1-7. [CrossRef]

7. Hasegawa, R.; Kawamura, K.; Choi, H.G.; Hama, Y. Influence of Frost Damage on Tensile Properties of Premixed Fiber Reinforced Polymer Cement Mortar. Proc. Concr. Struct. Scenar. JSMS 2017, 17, 419-424.

8. Kawamura, K.; Hasegawa, R.; Choi, H.G.; Hama, Y. Setting Shrinkage Properties of Urea-Mixed Fiber Reinforced Polymer Cement Mortar (FRPCM). Summ. Tech. Pap. Annu. Meet. 2017, A-1, 229-230.

9. AIJ. Recommendation for Practice of Concrete with Portland Cement and Ground Granulated Blast-Furnace Slag; Architectural Institute of Japan: Tokyo, Japan, 2001.

10. Saito, K.; Koyama, A.; Kikuchi, M. Study on Effect of Silicone Oil on Durability of Concrete; Architectural Institute of Japan (AIJ) Tournament Academic Lecture Synopsis Collection A-1 Materials and Construction; Architectural Institute of Japan: Tokyo, Japan, 2004; pp. 1166-1168.

11. Saito, K.; Koyama, A.; Kikuchi, M.; Furuoya, H. Study on Effect of Silicone Oil Water-Repellent Agent on Durability of Several Kinds of Concrete (Part 2. Durability); Architectural Institute of Japan (AIJ) Tournament Academic Lecture Synopsis Collection A-1 Materials and Construction; Architectural Institute of Japan: Tokyo, Japan, 2005; pp. 449-450.

12. Matsushita, F.; Aono, Y.; Shibata, S. Carbonation Resistance of Water-Repellent Autoclaved Aerated Concrete. J. Soc. Inorg. Mater. 2004, 11, 219-233.

13. Kishimoto, G.; Kim, J.H.; Choi, H.G.; Hama, Y. Influence of Silicone Oil on Durability of Portland Blast Furnace Slag Cement Mortar. J. Adv. Concrete Technol. 2018, 16, 110-123. [CrossRef]

14. JIS R 5021. Physical Testing Methods for Cement; Japan Concrete Institute: Tokyo, Japan, 2015.

15. JIS A 1128. Method of Test for Air Content of Fresh Concrete by Pressure Method; Japan Concrete Institute: Tokyo, Japan, 2014.

16. JIS A 1108. Method of Test for Compressive Strength of Concrete; Japan Concrete Institute: Tokyo, Japan, 2006.

17. Lamond, J.F.; Pielert, J.H. Significance of Tests and Properties of Concrete E Concrete-Making Materials; ASTM International: West Conshonkocken, PA, USA, 2006.

18. NEXCO Testing Methods Vol. 4 Structure Tests (Testing Methods 432); Expressway Specification by Japanese expressway company; NEXCO: Tokyo, Japan, 2012. 
19. JIS A 1129-3. Methods of Measurement for Length Change of Mortar and Concrete (Part 3: Method with Dial Gauge); Japan Concrete Institute: Tokyo, Japan, 2010.

20. JIS S 009-2012. Method of Test for Restrained Expansion of Expansive Concrete Using a Cylindrical Mold; Japan Concrete Institute: Tokyo, Japan, 2012.

21. JIS A 1153. Method of Accelerated Carbonation Test for Concrete; Japan Concrete Institute: Tokyo, Japan, 2012.

22. JIS A 1148. Method of Test for Resistance of Concrete to Freezing and Thawing; Japan Concrete Institute: Tokyo, Japan, 2010.

23. Kurihara, R.; Maruyama, I. Experimental Study on Relationship of the Additive Concentration of Shrinkage Reducing Agent and Dry Shrinkage Strain. Cem. Sci. Concr. Technol. 2015, 69, 118-123. [CrossRef]

24. Kishimoto, G.; Kim, J.H.; Choi, H.G.; Hama, Y. Influence of Silicone Oil on Carbonation Resistance, Drying Shrinkage and Frost Resistance of Blast Furnace Slag Cement Mortar. Proc. Concr. Struct. Scenar. JSMS 2017, 17, 351-356.

25. Miguel, Á.S.; Esteban, E.; Cristina, A.; Daniel del, B. Effect of curing time on granulated blast-furnace slag cement mortars carbonation. Cem. Concr. Compos. 2018, 90, 257-265.

(C) 2019 by the authors. Licensee MDPI, Basel, Switzerland. This article is an open access article distributed under the terms and conditions of the Creative Commons Attribution (CC BY) license (http://creativecommons.org/licenses/by/4.0/). 